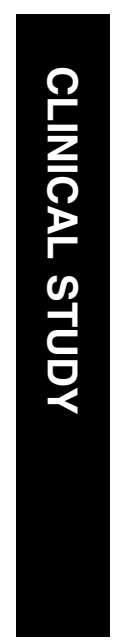

\section{A study to explore the risk factors for the early onset of cataract in India}

\begin{abstract}
Purpose The aim of this study was to identify risk factors for the development of cataract in young patients.

Settings The study was undertaken at Iladevi Cataract and IOL Research Centre, Ahmedabad, Gujarat, India.

Methods In a clinic-based observational study, 340 consecutive patients in the age group of 30-45 years presenting with nuclear, cortical, posterior subcapsular (PSC), mixed, and posterior polar cataract were prospectively studied. A detailed history regarding sunlight
\end{abstract}

\section{Introduction}

Keywords: presenile cataract; risk factors

Received: 22 October 2008 Accepted in revised form: 5 May 2009

Published online: 12 June 2009

Financial interest: None Proprietary interest: None
Cataract has a multifactorial aetiology with genetic, ${ }^{1}$ sociodemographic, ${ }^{2}$ behavioral, and

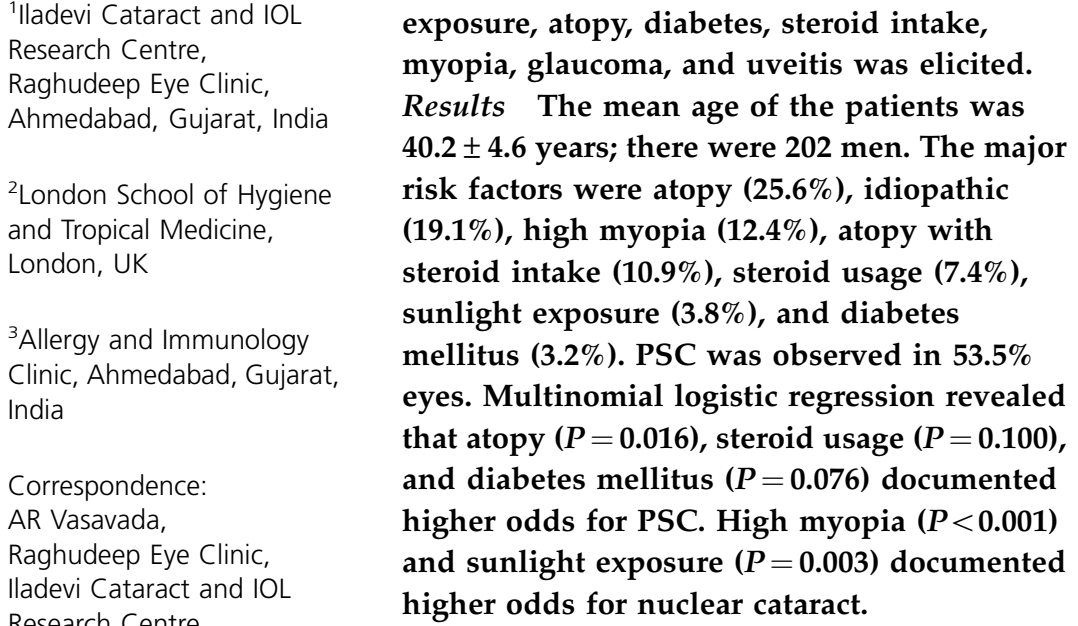

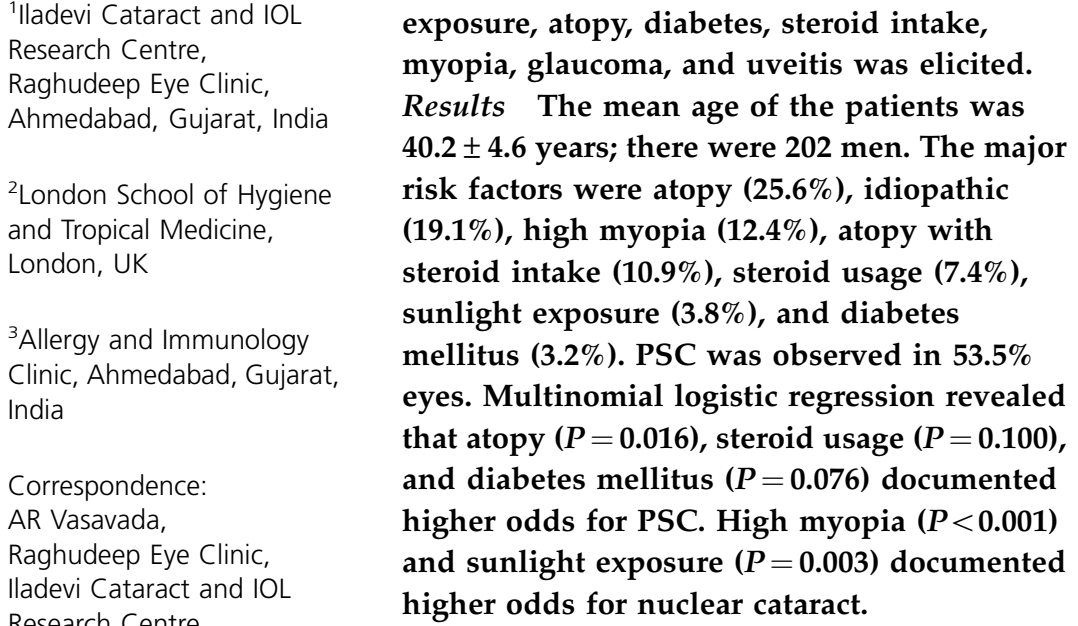

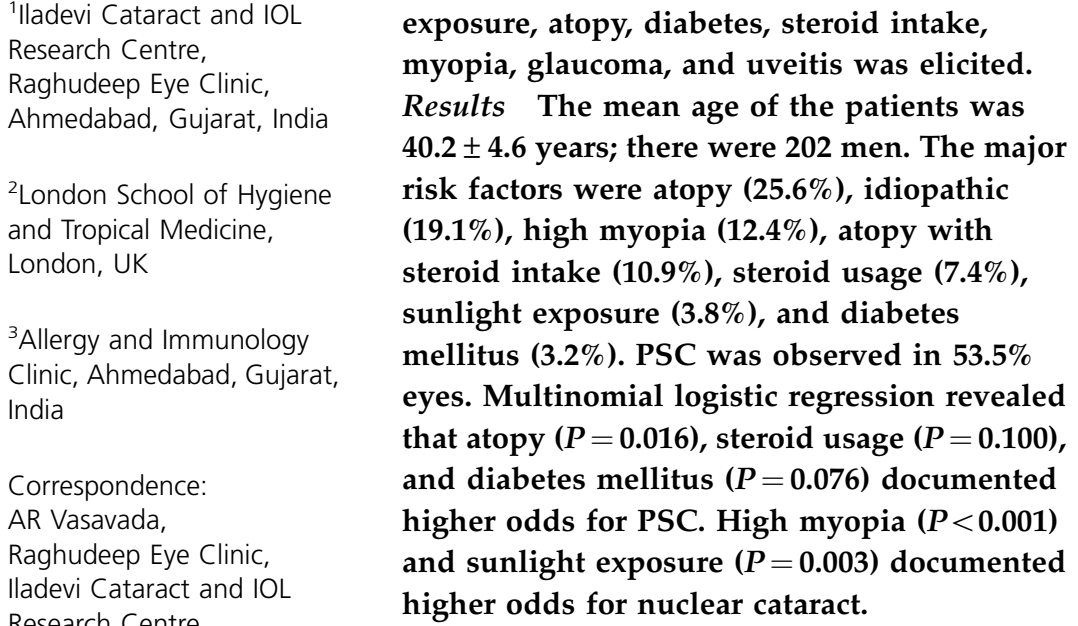

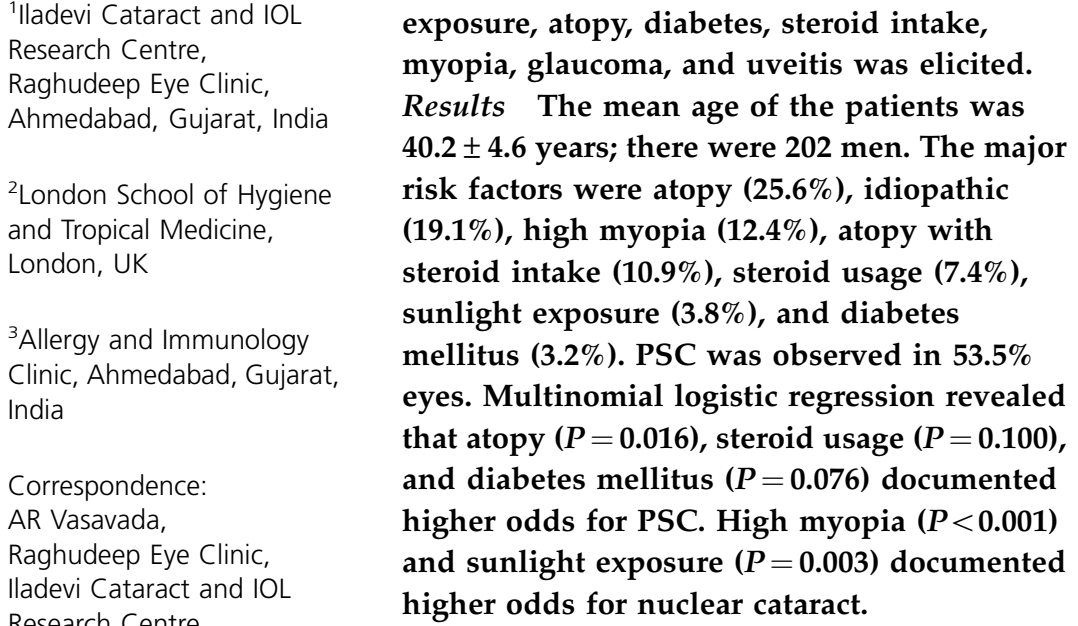

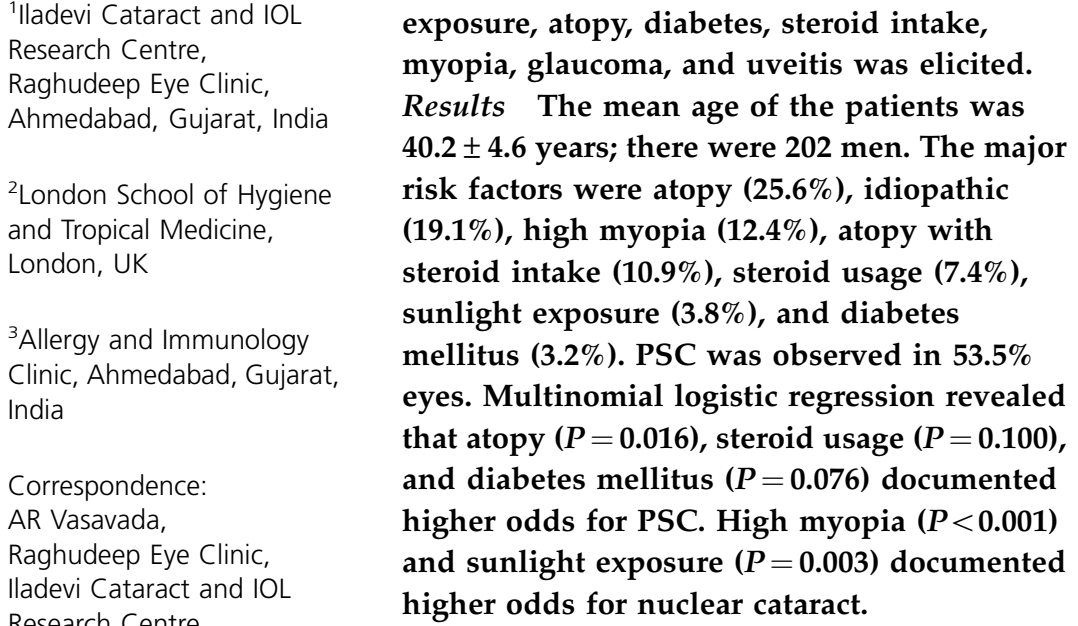

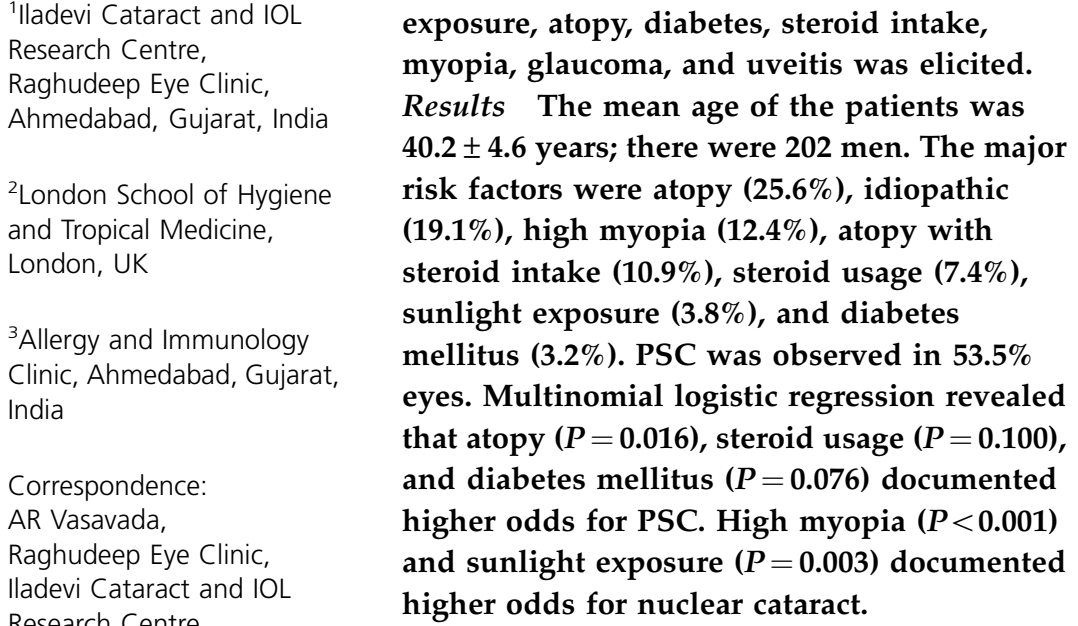

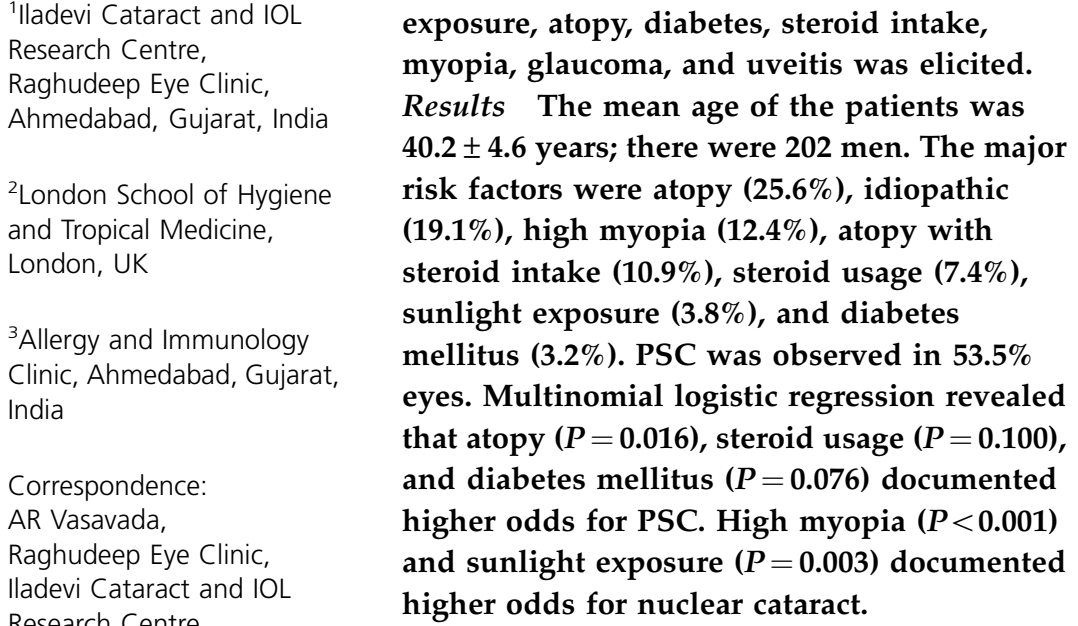

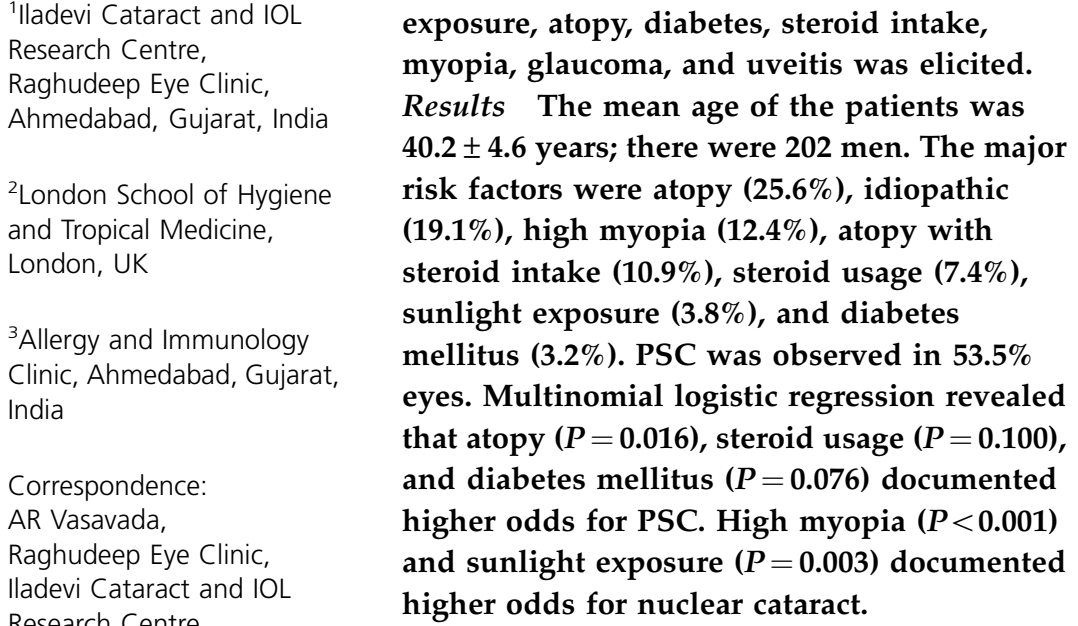

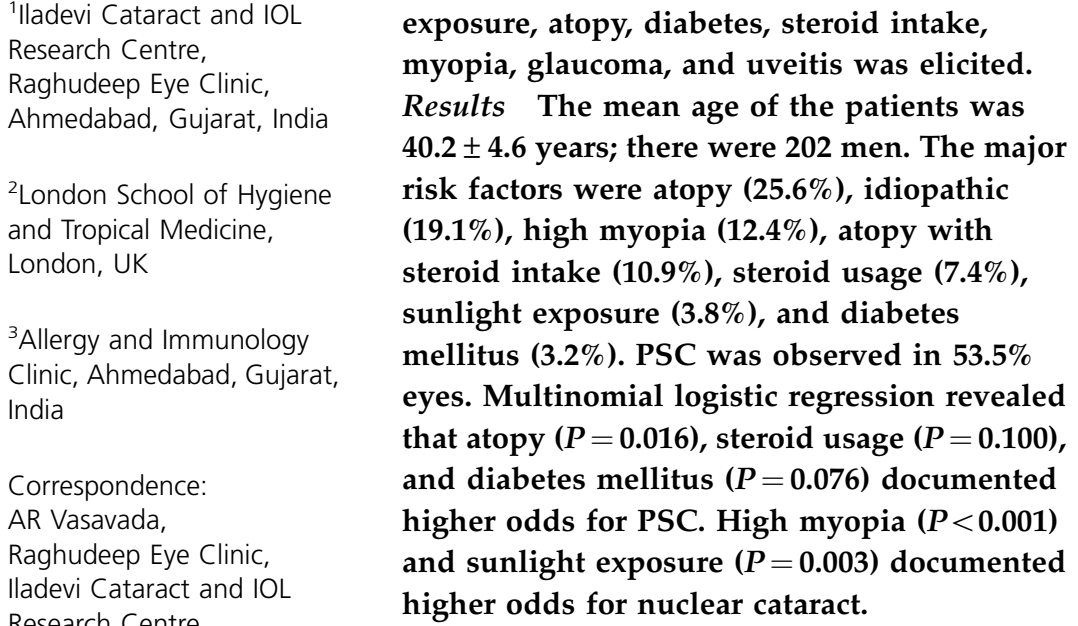

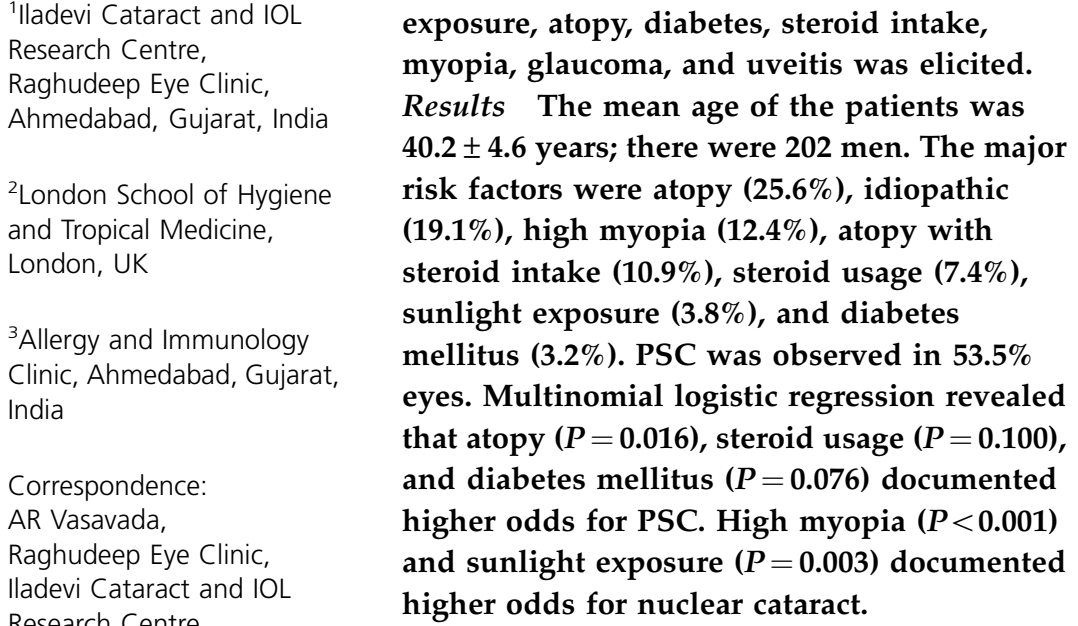

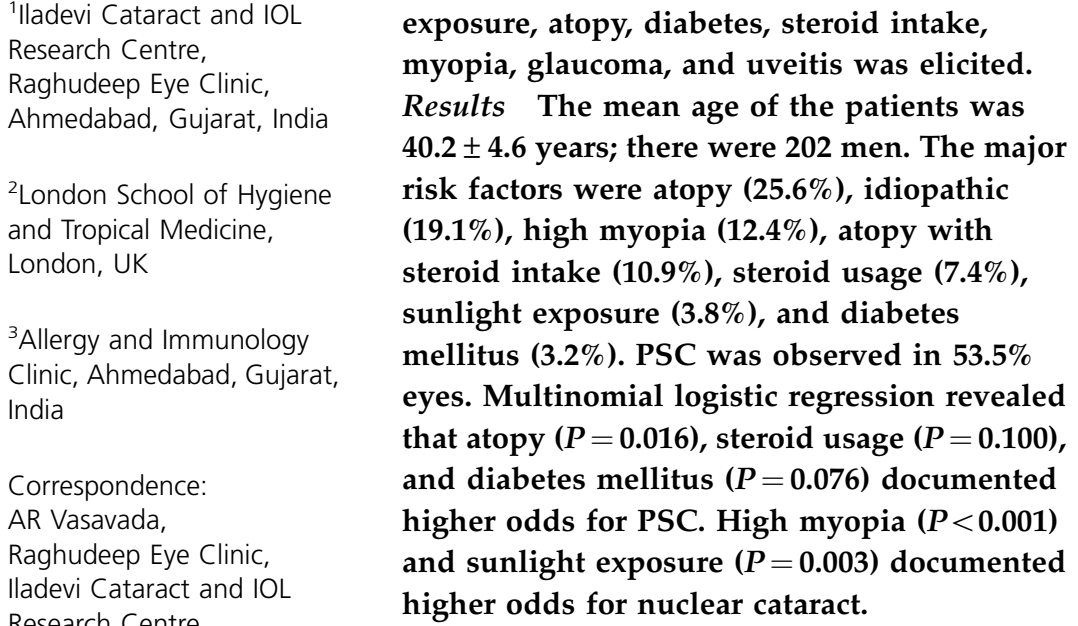

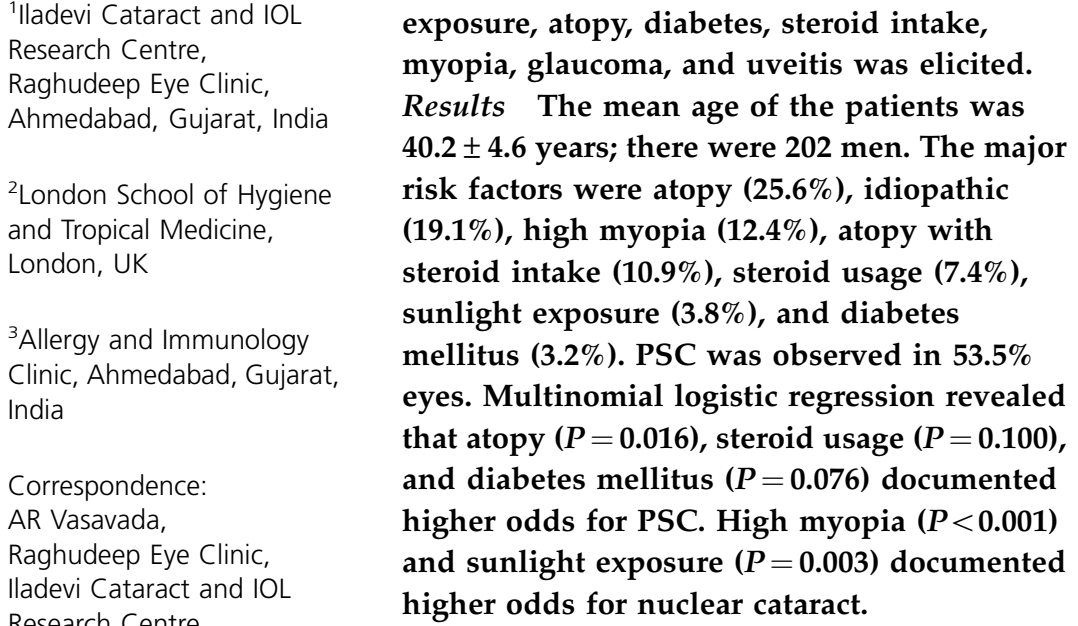

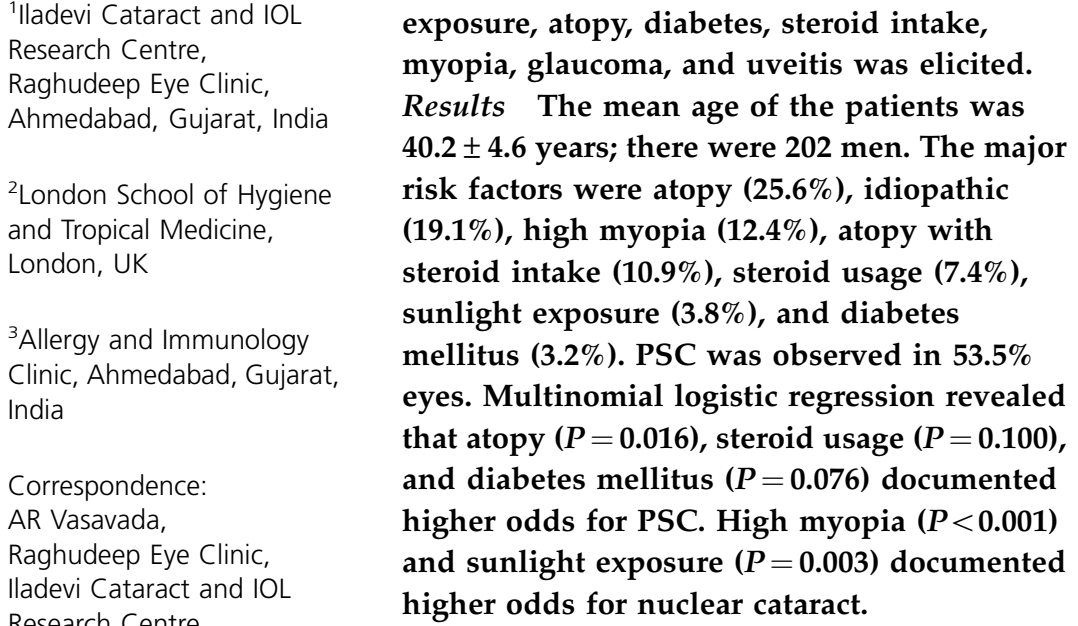

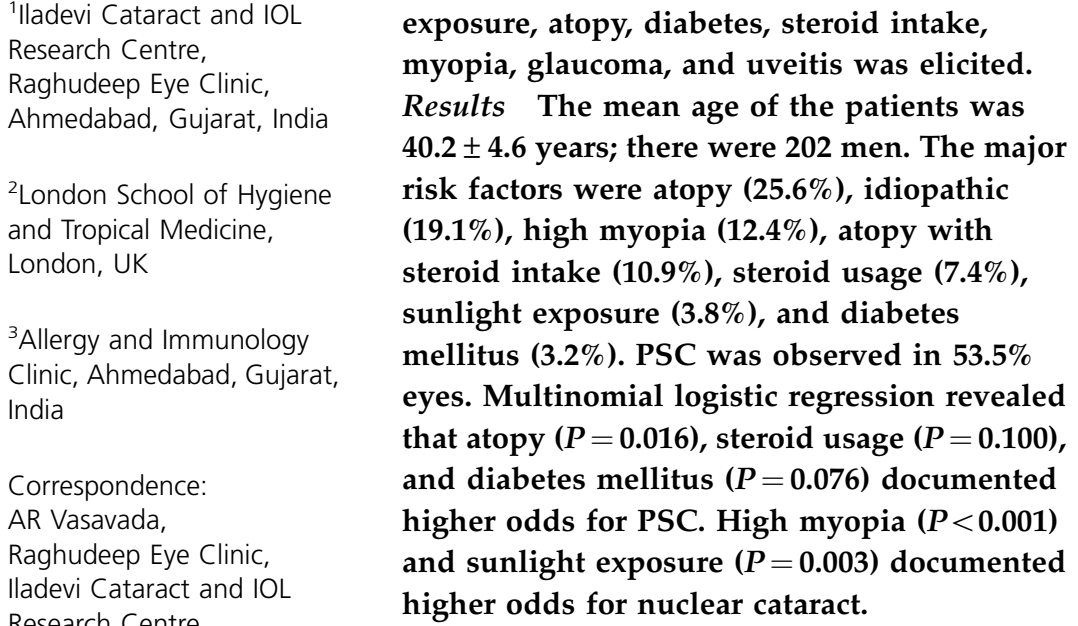

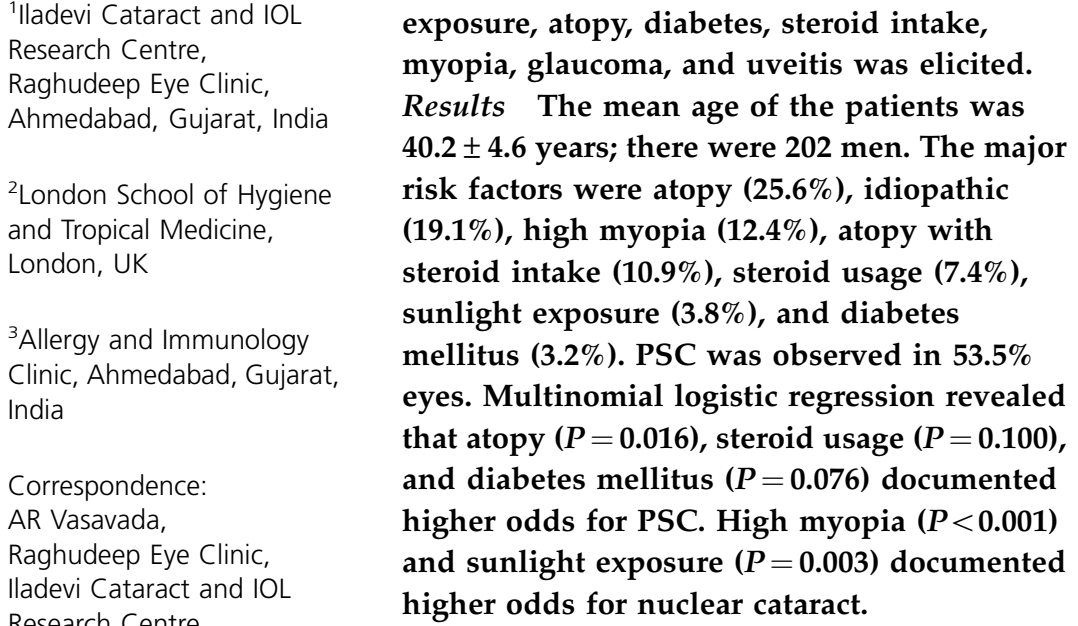

Conclusion Atopy was found to be the most common risk factor associated with the development of cataract in young individuals. PSC was the predominant type of cataract prevalent in young patients.

Eye (2010) 24, 686-694; doi:10.1038/eye.2009.137; published online 12 June 2009 Gurukul Road,

Memnagar,

Gujarat 380 052,

Tel: + 9179274923 03;

Fax: + 9179274112 00;
}

abhayvasavada.com

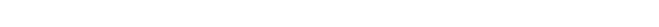

MR Praveen', GD Shah', AR Vasavada', PG Mehta ${ }^{1}$, C Gilbert ${ }^{2}$ and G Bhagat ${ }^{3}$

environmental factors ${ }^{3,4}$ all being implicated. Although it is likely that these factors interact with each other, age is still the single most important risk factor for cataract. In India, almost $80 \%$ of blindness is attributed to cataract and there is a high prevalence of lens opacities. 5,6 Moreover, lens opacities have an earlier age of onset in India compared with industrialized countries. ${ }^{7,8}$ For example, data from a study carried out in Punjab showed that the age-specific prevalence of cataract in India was three to six times higher than that in the Framingham Eye study in the United States. These findings suggest that the Indian population is either widely exposed to environmental risk factors (ultraviolet (UV) light, nutritional deficiencies, severe dehydration from diarrhoea/heatstroke) and/or there is a genetic predisposition to cataract. ${ }^{9-11}$ The search for modifiable risk factors that affect the occurrence of cataract has prompted investigators to explore possible links between cataract and diabetes, hypertension, body mass index, drug usage, severe dehydrational crises, gender, smoking, exposure to UV light, childbearing, and socioeconomic factors. ${ }^{1-4,10-18}$

Very few studies have been undertaken to explore risk factors for presenile cataract and they indicate that nearly $50 \%$ of the participants were exposed to at least one known risk factor including trauma, intraocular inflammation, diabetes mellitus, and the use of steroids. ${ }^{19-21}$ We believe that it is worth investigating presenile cataract in developing countries, as this group may be exposed to potentially modifiable risk factors. For example, studies of presenile cataract in India have shown associations between severe dehydrational crises and childbearing. ${ }^{10-12,22}$

The present study was undertaken to develop a methodology and study instruments that can be later used in a case-control study to explore associations between presenile cataract and risk factors among individuals aged 30-45 years. 
The study was undertaken at the Iladevi Cataract and IOL Research Centre, Ahmedabad, Gujarat, India. This centre provides comprehensive tertiary eye care and training in paediatric and adult cataract surgery. The catchment area includes Gujarat and its surrounding states (ie Rajasthan, Madhya Pradesh, Maharashtra, West Bengal, and Assam).

\section{Materials and methods}

In this prospective, clinic-based observational study, 340 consecutive patients in the age groups of 30-45 years with unilateral or bilateral morphologically similar cataract were recruited. Those with a history of intraocular surgery or ocular trauma were excluded. Informed consent was obtained from all participants. After dilating the pupils, the eyes of all the participants were examined at the slit lamp using standardized illumination and magnification. A single observer (MRP) used direct observation and retroillumination to determine the type of cataract. Cataract was categorized as nuclear, cortical, posterior subcapsular (PSC), posterior polar, or mixed cataract. The axial length (AXL) was measured 10 times in each eye using an A scan (OcuScan, Alcon) and an average value obtained. Intraocular pressures were measured by applanation tonometry and all the participants underwent a dilated fundus examination using indirect ophthalmoscopy.

An allergy specialist (GPB) developed a standardized questionnaire for this study, which was based on a questionnaire used routinely by chest physicians in the Vallabhbhai Patel Chest Institute, University of Delhi. In the present study, the atopy questionnaire was used to diagnose asthma, atopy, and allergic disorders.

(Figure 1). The questionnaire included symptoms of rhinitis, itching and seasonality of itching, history of asthma, eczema, dermatitis and the age of onset, and reaction to recognized allergens such as pollen. One observer (GDS) interviewed all the participants and elicited detailed information regarding sunlight exposure, steroid intake, diabetes, myopia, and uveitis and filled out the atopy questionnaire. Those participants who reported five to six symptoms of atopy were referred to the same allergy specialist who confirmed whether they were atopic and assigned a severity score after weighting their symptoms (Figure 2). The score values ranged from 0 to 28 and the different degrees of severity were defined as follows: 0-6 no atopy, 7 mild atopy, 8-14 moderate atopy, 15-21 severe atopy, and 22-28 very severe atopy. Participants were categorized as having significant sunlight exposure if their occupation meant they spent more than $8 \mathrm{~h}$ a day outdoors for more than 5 days a week for more than 8-10 years. Diabetes was diagnosed based on the medical history of the
An Evaluation of Scores of Risk Factors for Atopy

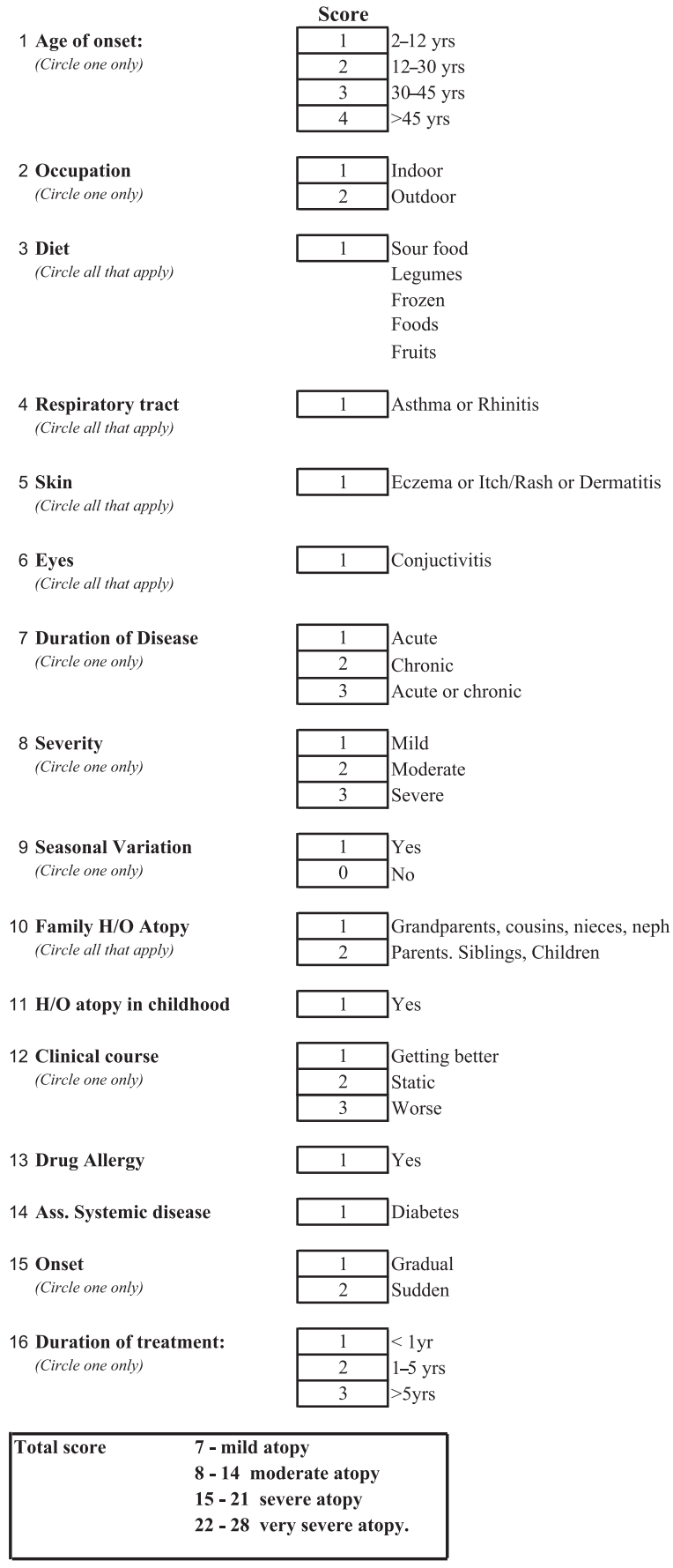

Figure 1 Questionnaire to evaluate risk factors.

patient and verified against the physicians' treatment records. Steroid intake was classified as oral, inhaled, injectable, or topical used for at least 4 months. Participants were categorized as having high myopia if their AXL was more than $26 \mathrm{~mm}$. Patients in whom none of the risk factors were observed were placed into a separate group called the idiopathic category. 


\section{Atopy questionnaire}

1 Name

\section{Date of birth}

3 Age

4 Sex

\begin{tabular}{|l|l|l|}
\multicolumn{1}{ll}{ first } & \multicolumn{1}{c}{ middle last } \\
\hline & & \\
\hline
\end{tabular}

Study number
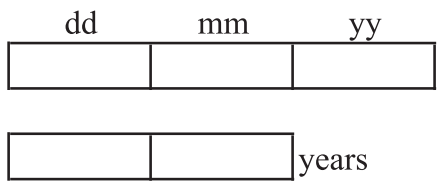

Male
Female

5 Occupation:

6 Complaints :

a Respiratory:

(Circle all that apply)
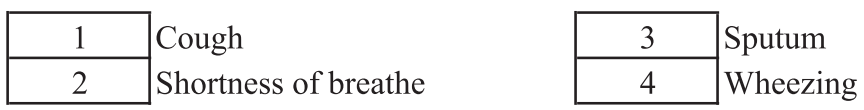

b Upper Respiratory Tract (Circle all that apply)

\begin{tabular}{|l|l}
\hline 1 & Sneezing \\
\cline { 1 - 1 } 2 & Running nose \\
\cline { 1 - 1 } 3 & Blocked nose \\
\cline { 1 - 2 } 4 & Itching nose \\
\hline
\end{tabular}

\begin{tabular}{|c|c|}
\hline 5 & Itching eyes \\
\hline 6 & Itching palate \\
\hline 7 & Itching ears \\
\hline
\end{tabular}

c Gastrointestinal

(Circle all that apply)

\begin{tabular}{|l|l}
\hline 1 & Abdominal cramps after food \\
\cline { 1 - 1 } 2 & Mucus in stools/Diarrhea \\
\hline
\end{tabular}

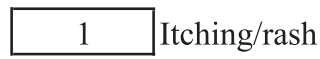

d Skin

(Circle all that apply)

7 Other Complains

(Circle all that apply)

\begin{tabular}{|l|l}
\hline 1 & Headache \\
\cline { 1 - 1 } 2 & Giddiness \\
\cline { 1 - 1 } 3 & Fever \\
\hline
\end{tabular}

\begin{tabular}{|c|c|}
\hline 1 & Seasonal \\
\hline 2 & Perennial \\
\hline 3 & Irregular \\
\hline
\end{tabular}

9 Severity of symptoms:

(Circle one only)

\begin{tabular}{|l|l}
\hline 1 & Severe \\
\cline { 1 - 1 } 2 & Moderate \\
\cline { 1 - 1 } 3 & Mild \\
\hline
\end{tabular}

10 Indicate months when affected

\begin{tabular}{|c|}
\hline Jan \\
\hline Feb \\
\hline Mar \\
\hline Apr \\
\hline
\end{tabular}

\begin{tabular}{|c|}
\hline May \\
\hline Jun \\
\hline Jul \\
\hline Aug \\
\hline
\end{tabular}

8 Seasonality

(Circle one only)
2 Angio-oedema

\section{Food sensitivity}

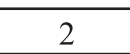

Figure 2 Atopy evaluation score. 
11 If seasonal

(Circle one only)

\begin{tabular}{|l|l}
\hline 1 & Constant \\
\hline 2 & Intermittent
\end{tabular}

12 Likely Causative Agents:

a Inhalants:

(Circle all that apply)

\begin{tabular}{|l|l}
\hline 1 & Pollen \\
\hline 2 & House dust \\
\hline 3 & Cotton dust \\
\cline { 1 - 1 } 4 & Paper dust \\
\cline { 1 - 1 } 5 & Wheat dust \\
\cline { 1 - 2 } 6 & House dust mite
\end{tabular}

\begin{tabular}{|c|l}
\hline 7 & Air in cellars \\
\cline { 1 - 1 } 8 & Animal dander \\
\cline { 1 - 1 } 9 & Human dander \\
\cline { 1 - 1 } 10 & Fumes \\
\cline { 1 - 1 } 11 & Perfume \\
\hline
\end{tabular}

b Ingestants

(Circle all that apply)

\begin{tabular}{|l|l}
\hline 1 & Food \\
\cline { 1 - 1 } 2 & $\begin{array}{l}\text { Drugs } \\
\text { Chemicals }\end{array}$ \\
\cline { 1 - 1 } 3 & $\begin{array}{l}\text { Soap } \\
\text { Cosmetics }\end{array}$ \\
\cline { 1 - 2 } 5 & Cosment
\end{tabular}

\begin{tabular}{|l|l}
\hline 6 & Synthetic fibres \\
\hline 7 & Plastic \\
\cline { 1 - 1 } 8 & Petroleum products \\
\cline { 1 - 1 } 9 & Others \\
\hline
\end{tabular}

c Contacts

(Circle all that apply)

\begin{tabular}{|c|c|}
\hline 1 & Dyes \\
\hline 2 & Chemicals \\
\hline 3 & Drugs \\
\hline 4 & Soap \\
\hline 5 & Cosmetics \\
\hline
\end{tabular}

\begin{tabular}{|l|l}
\hline 6 & Synthetic fibres \\
\hline 7 & Plastic \\
\hline 8 & Petroleum products \\
\cline { 1 - 1 } 9 & Others \\
\hline
\end{tabular}

d Physical agents

(Circle all that apply)

\begin{tabular}{|l|l}
\hline 1 & Cold \\
\cline { 1 - 1 } 2 & heat \\
\cline { 1 - 1 } 3 & Fan \\
\cline { 1 - 1 } 4 & Rain \\
\hline
\end{tabular}

\begin{tabular}{|l|l}
\hline 5 & Smoke \\
\hline 6 & Storms \\
\cline { 1 - 1 } 7 & Change of season
\end{tabular}

e Psychological factors

(Circle all that apply)

\begin{tabular}{|l|l}
\hline 1 & Emotional upset \\
\hline 2 & Anger \\
\hline 3 & Frustration \\
\hline
\end{tabular}

\begin{tabular}{|l|l}
\hline 4 & Anxiety \\
\cline { 1 - 1 } 5 & Depression \\
\cline { 1 - 1 } 6 & Other
\end{tabular}

$f$ Exercise

(Circle one only)

\begin{tabular}{|c|c|}
\hline 1 & Mild exercise / work \\
\hline 2 & Moderate exercise / work \\
\hline 3 & Heavy exercise / work \\
\hline
\end{tabular}

12 Investigations:

\begin{tabular}{|l|l|l}
\hline 1 & & Eosinophil count \\
\hline 2 & Serum IgE \\
\hline
\end{tabular}

Figure 2 Continued.

Multinomial logistic regression was applied taking into consideration all the risk factors to obtain the odds associated with each risk factor and to determine odds for a combination of risk factors. Using a multivariate model, we carried out further analysis using multinomial logistic regression to find an association between types of cataract and various risk factors (Table 3). Patients with mixed and cortical cataract were combined into a single category representing 'other types,' and we compared the influence of risk factors on nuclear cataract, PSC, and posterior polar cataract using these 'other types' as a reference category. This exercise was attempted to find 
Table 1 Distribution of exposures

\begin{tabular}{lrr}
\hline Risk factor & $\mathrm{N}$ & $\%$ \\
\hline Atopy alone or with other exposures & & \\
Atopy (of any type) alone & 87 & 25.6 \\
Atopy (of any type) + steroids & 37 & 10.9 \\
Atopy (of any type) + UV light & 8 & 2.4 \\
Atopy (of any type) + myopia & 7 & 2.1 \\
Atopy (of any type) + diabetes mellitus & 10 & 2.9 \\
Atopy (of any type) + steroids + myopia & 6 & 1.8 \\
Atopy (of any type) + UV light + steroids & 1 & 0.3 \\
Family history of atopy & 7 & 2.1 \\
Family history of atopy + glaucoma & 1 & 0.3 \\
Subtotal & 164 & 48.2 \\
& & \\
Other exposures & & \\
Steroids & 25 & 7.4 \\
UV light & 13 & 3.8 \\
Diabetes mellitus & 11 & 3.2 \\
Family history of cataract & 4 & 1.2 \\
Uveitis & 4 & 1.2 \\
Family history of cataract + steroids + uveitis & 4 & 1.2 \\
Glaucoma & 2 & 0.6 \\
Glaucoma + uveitis & 2 & 0.6 \\
Subtotal & 65 & 19.1 \\
Idiopathic & & \\
Other risk factors & 65 & 19.1 \\
Total & 46 & 13.5 \\
\hline
\end{tabular}

risk factors associated with nuclear cataract, PSC, and posterior polar as compared with the 'other types' mentioned above. The category 'other types' was used as a reference as these types of cataract rarely occur in young patients thereby making it an ideal choice for use as a reference category.

\section{Results}

The total study population was 366 patients. Of 366 patients, 290 had bilateral cataract and 76 had unilateral cataract. Of 290 patients, 264 had bilateral similar cataract but only one eye of each patient was randomly selected for the study. Further 26 patients with bilateral dissimilar cataracts were excluded from the study. So the final study population comprised 340 eyes of 340 patients. All these patients were distributed into all the above-mentioned categories based on the risk factors identified in them. Of the 340 patients, 202 were men and 138 were women. The mean age of the study population was $40.28 \pm 4.65$ years. The distribution of risk factors in the present study is shown in Table 1. Atopy was the single most common exposure followed by idiopathic $(65,19.1 \%)$. Atopy was found in $87(25.6 \%)$ patients and it was judged as the dominant risk factor for cataract. A history of atopy was reported by 164 participants $(48.3 \%)$ either alone $(87,25.6 \%)$ or in combination with other exposures $(77,22.7 \%)$ (Table 2$)$. Asthma and allergic dermatitis were the most common forms of atopy (Table 2).

In the present study, overall 33 patients were categorized into mild atopy whereas 57 patients were with moderate, 49 with severe, and 25 with very severe degree of atopy. The other risk factors documented in decreasing order were idiopathic in $65(19.1 \%)$ patients, high myopia in $42(12 \%)$, atopy with steroid-induced cataract in $37(10.9 \%)$, steroid-induced cataract in $25(7.4 \%)$, sunlight exposure in $13(3.8 \%)$, and diabetes mellitus in $11(3.2 \%)$. In the study population, the most common type of cataract predominantly observed was PSC in $182(53.5 \%)$ eyes followed by nuclear cataract in $71(20.9 \%)$, mixed cataract in $57(16.8 \%)$, and posterior polar cataract in $30(8.8 \%)$. The distribution of cataract with other risk factors using different combinations is described in Table 3. In the atopy category, PSC was predominant in $49(56.3 \%)$ eyes whereas in the idiopathic category it was found in $36(55.4 \%)$ eyes. PSC was predominant in $33(89.2 \%)$ eyes with atopy on steroid intake and in $11(44 \%)$ eyes with steroid-induced cataract for various reasons. In eyes with PSC and mixed lens opacities, atopy was the most common associated risk factor (in 49 eyes, 56.3\%), whereas in eyes with nuclear cataract, myopia was the most common risk factor (38.5\%). In most cases posterior polar cataract was idiopathic (40\%), whereas in patients in the idiopathic category, PSC and posterior polar cataract were most common. Using a multivariate model, we carried out further analysis using multinomial logistic regression to find an association between types of cataract and various risk factors (Table 3 ). The mixed and cortical cataracts were merged into a single category representing 'other types', and we compared the influence of risk factors against nuclear cataract, PSC, and posterior polar. Atopy

Table 2 Types of atopy in participants confirmed as atopic

\begin{tabular}{lrr}
\hline & $\mathrm{N}$ & $\%$ \\
\hline Asthma & 25 & 15.2 \\
Allergic dermatitis & 25 & 15.2 \\
Allergic conjunctivitis & 18 & 11.0 \\
Atopic rhinitis & 12 & 7.3 \\
Food allergy & 12 & 7.3 \\
Drug allergy & 10 & 6.1 \\
Cloth allergy & 3 & 1.8 \\
Allergic conjunctivitis + rhinitis & 22 & 13.4 \\
Allergic dermatitis + rhinitis & 18 & 11.0 \\
Allergic conjunctivitis + dermatitis & 9 & 5.5 \\
Asthma + dermatitis & 5 & 3.1 \\
Dermatitis + rhinitis + conjunctivitis & 5 & 3.1 \\
Total & 164 & 100 \\
\hline
\end{tabular}


Table 3 Association between atopy and other risk factors based on the type of cataract

\begin{tabular}{|c|c|c|c|c|c|c|c|c|c|c|}
\hline & \multicolumn{2}{|c|}{ PSC } & \multicolumn{2}{|c|}{ Nuclear } & \multicolumn{2}{|c|}{$P P$} & \multicolumn{2}{|c|}{ Mixed } & \multicolumn{2}{|c|}{ All } \\
\hline & $\mathrm{N}$ & $\%$ & $\mathrm{~N}$ & $\%$ & $\mathrm{~N}$ & $\%$ & $\mathrm{~N}$ & $\%$ & $\mathrm{~N}$ & $\%$ \\
\hline Idiopathic & 36 & 19.8 & 6 & 8.5 & 12 & 40.0 & 11 & 19.3 & 65 & 19.1 \\
\hline \multicolumn{11}{|l|}{ Atopy confirmed } \\
\hline Atopy alone & 49 & 26.9 & 9 & 12.7 & 11 & 36.7 & 18 & 31.6 & 87 & 25.6 \\
\hline Atopy + steroids & 33 & 18.1 & 1 & 1.4 & 0 & 0 & 3 & 5.3 & 37 & 10.9 \\
\hline Atopy + diabetes & 6 & 3.3 & 0 & 0 & 2 & 6.7 & 2 & 3.5 & 10 & 2.9 \\
\hline Atopy + UVL & 3 & 1.6 & 5 & 7.0 & 0 & 0 & 0 & 0 & 8 & 2.4 \\
\hline Atopy + myopia & 2 & 1.1 & 5 & 7.0 & 0 & 0 & 0 & 0 & 7 & 2.1 \\
\hline Atopy + steroids + myopia & 2 & 1.1 & 4 & 5.6 & 0 & 0 & 0 & 0 & 6 & 1.8 \\
\hline Atopy + UVL + steroids & 0 & 0 & 1 & 1.4 & 0 & 0 & 0 & 0 & 1 & 0.3 \\
\hline Family history of atopy & 4 & 2.2 & 0 & 0 & 0 & 0 & 3 & 5.3 & 7 & 2.1 \\
\hline FHA + glaucoma & 1 & 0.5 & 0 & 0 & 0 & 0 & 0 & 0 & 1 & 0.3 \\
\hline Subtotal & 100 & 54.9 & 25 & 35.2 & 13 & 43.3 & 26 & 45.6 & 164 & 48.2 \\
\hline \multicolumn{11}{|l|}{ No atopy } \\
\hline Myopia & 8 & 4.4 & 25 & 35.2 & 4 & 13.3 & 5 & 8.8 & 42 & 12.4 \\
\hline Steroids & 11 & 6.0 & 4 & 5.6 & 0 & 0 & 10 & 17.5 & 25 & 7.4 \\
\hline UVL & 5 & 2.7 & 4 & 5.6 & 0 & 0 & 4 & 7.0 & 13 & 3.8 \\
\hline Diabetes & 7 & 3.8 & 3 & 4.2 & 1 & 3.3 & 0 & 0 & 11 & 3.2 \\
\hline FHC & 4 & 2.2 & 0 & 0 & 0 & 0 & 0 & 0 & 4 & 1.2 \\
\hline FHC + steroids + uveitis & 4 & 2.2 & 0 & 0 & 0 & 0 & 0 & 0 & 4 & 1.2 \\
\hline Uveitis & 4 & 2.2 & 0 & 0 & 0 & 0 & 0 & 0 & 4 & 1.2 \\
\hline Myopia + glaucoma & 0 & 0 & 2 & 2.8 & 0 & 0 & 0 & 0 & 2 & 0.6 \\
\hline Steroid + myopia & 0 & 0 & 2 & 2.8 & 0 & 0 & 0 & 0 & 2 & 0.6 \\
\hline Glaucoma & 2 & 1.1 & 0 & 0 & 0 & 0 & 0 & 0 & 2 & 0.6 \\
\hline Glaucoma + uveitis & 1 & 0.5 & 0 & 0 & 0 & 0 & 1 & 1.8 & 2 & 0.6 \\
\hline Subtotal & 46 & 25.3 & 40 & 56.3 & 5 & 16.7 & 20 & 35.1 & 111 & 32.6 \\
\hline Total & 182 & 100 & 71 & 100 & 30 & 100 & 57 & 100 & 340 & 100 \\
\hline
\end{tabular}

DM, diabetes mellitus; FHA, family history of atopy; FHC, family history of cataract; mixed, a combination of nuclear + cortical + posterior subcapsular cataract; PP, posterior polar; PSC, posterior subcapsular cataract; UVL, ultraviolet light.

documented higher odds for PSC $(P=0.016)$ attaining statistical significance compared to 'other types'. Steroidinduced cataracts $(P=0.100)$, diabetes $(P=0.076)$, and uveitis $(P=0.121)$ also documented higher odds for PSC but did not attain statistical significance compared to 'other types'. The idiopathic category showed increased odds for both PSC $(P=0.038)$ and posterior polar $(P=0.203)$; however, the impact of occurrence of posterior polar in the idiopathic group was stronger than the impact of PSC cataract. High myopia $(P<0.001)$ and UV light exposure $(P=0.003)$ expressed increased odds for nuclear cataract when compared to 'other types' attaining statistical significance. (Table 4).

\section{Discussion}

There is a paucity of peer-reviewed literature on risk factors for presenile cataract in India. A case-control study carried out in India indicated a strong association between dehydrational crises and presenile cataract. ${ }^{22}$ On the basis of these observations, it was concluded that childbearing may substantially increase the risk of cataract among women of childbearing age in India. ${ }^{12}$ Because a few studies ${ }^{12,19,20}$ have already been carried out on the risk factors for cataract in young individuals, this preliminary communication has attempted to describe the risk factors associated with various types of cataract in individuals below 45 years.

In our present study, multiple risk factors were responsible for cataract formation. Cases with more than one risk factor for the development of cataract were placed in all the appropriate categories of this study. Even though other categories were possible based on different combinations of risk factors, they were ignored because very few patients fell into those categories. In the present study, to avoid the correlation effect, we have randomly recruited only one eye of each patient with bilateral similar cataract. Further we had to exclude patients with bilateral dissimilar cataract so as to avoid any overlap of the impact of risk factors on the development of cataract.

In our study, a surprisingly high proportion of participants were diagnosed as atopic, and atopy was more frequent among those with PSC cataract. Some 
forms of atopy such as atopic dermatitis ${ }^{23-28}$ can be complicated by cataract, but the association between atopy and presenile cataract has not yet been studied in developing countries. Although the causes of atopic dermatitis are unknown, cataract can develop and progress during periods when the dermatitis is active ${ }^{24,25}$ and lens opacities are often associated with severe manifestations of this disease. ${ }^{24,25}$ In a study from Japan, $19(12.4 \%)$ of 153 young adults with atopic dermatitis had cataract. ${ }^{23}$ In another study, authors reported that $10-25 \%$ of patients with atopic dermatitis had early onset of cataract that often occurred during exacerbations of the disease. ${ }^{29}$ In another study, $25 \%$ of patients with atopic dermatitis had cataract, with PSC cataract being the most common type $(50 \%)$ followed by anterior subcapsular cataract $(25 \%)$ and total opacities $(12.5 \%)$. $^{30,31}$ These authors also noted rapid progression of cataract during periods when the skin disease was active. ${ }^{29,30}$

A breakdown of the blood-aqueous barrier and frequent eye rubbing may also be contributory factors. ${ }^{32,33}$

A literature review of population-based studies on risk factors for cataract has failed to reveal atopy as a risk factor for the development of cataract even in young and age-related cataract. Although the atopy questionnaire used in this study has not been validated against other indicators of allergy (eg IgE and eosinophilia), all the participants reporting symptoms were interviewed and examined by an allergy specialist who confirmed the diagnosis. To our knowledge, only one validated atopy questionnaire has been reported in literature that was designed for alopecia and eczema.

In our study, only $19.1 \%$ of the participants did not report any of the risk factors we explored. We reported similar observations in an earlier prospective study of 150 consecutive patients with presenile cataract. ${ }^{34}$ In the present study, high myopia was also an important risk factor. In the young patients with cataract studied here, it was observed that nuclear sclerosis was the most frequent subgroup of high myopia. Similar findings have been reported from Taiwan where an AXL of $>27 \mathrm{~mm}$ was associated with an increased risk of cataract in individuals below 45 years. ${ }^{35}$ In another report, the authors described discrete nuclear sclerosis in young subjects with axial myopia as the cause of unexplained visual loss. ${ }^{36}$

Compared with other studies, ${ }^{37,38}$ we found that corticosteroid usage (either topical, oral, or systemic) was more frequent in our study population and in almost half

Table 4 Odds ratio associated with each risk factor by type of cataracts

\begin{tabular}{|c|c|c|c|c|c|c|c|c|}
\hline & \multirow[t]{2}{*}{$B$} & \multirow[t]{2}{*}{$S E$} & \multirow[t]{2}{*}{ Wald } & \multirow[t]{2}{*}{ d.f. } & \multirow[t]{2}{*}{ Sig. } & \multirow[t]{2}{*}{ Exp. (B) } & \multicolumn{2}{|c|}{$95 \% C I$} \\
\hline & & & & & & & Lower bound & Upper bound \\
\hline \multicolumn{9}{|l|}{ PSC } \\
\hline Atopy & 1.139 & 0.471 & 5.837 & 1 & $0.016^{*}$ & 3.124 & 1.240 & 7.871 \\
\hline Steroid & 0.764 & 0.464 & 2.712 & 1 & 0.100 & 2.148 & 0.865 & 5.334 \\
\hline Idiopathic & 1.299 & 0.625 & 4.317 & 1 & $0.038^{*}$ & 3.665 & 1.076 & 12.482 \\
\hline Myopia & 0.690 & 0.700 & 0.971 & 1 & 0.325 & 1.993 & 0.505 & 7.861 \\
\hline Diabetes & 1.549 & 0.872 & 3.156 & 1 & 0.076 & 4.708 & 0.852 & 26.011 \\
\hline Uveitis & 1.794 & 1.157 & 2.406 & 1 & 0.121 & 6.015 & 0.623 & 58.075 \\
\hline UV light & 0.382 & 0.746 & 0.262 & 1 & 0.609 & 1.465 & 0.339 & 6.322 \\
\hline \multicolumn{9}{|l|}{$N C$} \\
\hline Atopy & 0.842 & 0.562 & 2.246 & 1 & 0.134 & 2.321 & 0.772 & 6.981 \\
\hline Steroid & 0.604 & 0.601 & 1.008 & 1 & 0.315 & 1.829 & 0.563 & 5.939 \\
\hline Idiopathic & 1.115 & 0.821 & 1.846 & 1 & 0.174 & 3.051 & 0.610 & 15.245 \\
\hline Myopia & 3.536 & 0.742 & 22.70 & 1 & $0.000^{*}$ & 34.325 & 8.016 & 146.980 \\
\hline Diabetes & 1.835 & 1.054 & 3.031 & 1 & 0.082 & 6.262 & 0.794 & 49.392 \\
\hline Uveitis & -17.88 & 0.000 & & 1 & & $1.704 \mathrm{E}-08$ & $1.704 \mathrm{E}-08$ & $1.704 \mathrm{E}-08$ \\
\hline UV light & 2.357 & 0.796 & 8.776 & 1 & $0.003^{*}$ & 10.556 & 2.220 & 50.190 \\
\hline \multicolumn{9}{|l|}{$P P$} \\
\hline Atopy & 0.920 & 1.044 & 0.777 & 1 & 0.378 & 2.510 & 0.324 & 19.432 \\
\hline Steroid & -19.852 & 8994.22 & 0.000 & 1 & 0.998 & $2.389 \mathrm{E}-09$ & 0.000 & 0.000 \\
\hline Idiopathic & 1.504 & 1.181 & 1.623 & 1 & 0.203 & 4.501 & 0.445 & 45.520 \\
\hline Myopia & 1.174 & 1.176 & 0.997 & 1 & 0.318 & 3.235 & 0.323 & 32.409 \\
\hline Diabetes & 1.495 & 1.168 & 1.637 & 1 & 0.201 & 4.457 & 0.452 & 43.995 \\
\hline Uveitis & -16.947 & 0.000 & 0.000 & 1 & 0.000 & $4.366 \mathrm{E}-08$ & $4.366 \mathrm{E}-08$ & $4.366 \mathrm{E}-08$ \\
\hline UV light & -18.827 & 0.000 & 0.000 & 1 & 0.000 & $6.660 \mathrm{E}-09$ & $6.660 \mathrm{E}-09$ & $6.660 \mathrm{E}-09$ \\
\hline
\end{tabular}

NC, nuclear cataract; PSC, posterior subcapsular cataract; PP, posterior polar. Multinomial logistic regression using 'others cataracts' as reference category. ${ }^{*} P<0.05$ is statistically significant. 
the population this was associated with other exposures under study. In the present study, consumption of steroids for as little as 4 months was scored. We did not attempt to validate drug consumption. The usual methods of testing drug consumption such as blood and urine tests were not feasible in this case because our interests extended to drugs taken in the past. Validations were done either from the hospital records or from the general practitioners' notes. PSC cataract was the predominant type of cataract in the present study, which was similar to the observations made in other studies. ${ }^{37,38}$ Steroid compounds including topical drops, pills, and inhalers have been associated with significantly increased risk for lens opacity. ${ }^{37,38}$

Diabetes mellitus was diagnosed in $3.2 \%$ of participants, which may reflect the increasing incidence of diabetes in India. In our present study, PSC was predominant with diabetes mellitus. Similar observations on the association between diabetes and PSC have been reported in other studies. ${ }^{39-41}$ The function of UV light in the aetiology of cataract is controversial and difficult to study. In our study, only a minority of participants had an outdoor occupation. Lens opacification has been linked to ocular exposure to UV radiation particularly UV B. ${ }^{42}$ Few authors ${ }^{43,44}$ found a positive correlation between cataract prevalence and duration of sunlight exposure. In the present study, PSC followed by nuclear cataract was documented in patients experiencing occupational exposure to sunlight. However, we do not have sufficient data on the range of ocular exposure to determine the magnitude of any increase in the risk of incurring cataract. Further work in this area is clearly warranted.

Some of the limitations of this pilot study are that we did not use LOCS III or other recognized systems to classify and grade lens opacities. Further family histories of atopy were not validated and inquiries were not made about alcohol intake, smoking habits, or the socioeconomic status of the participants. The details of visual acuity were not documented. Further the patients did not have a cycloplegic refraction. There was no control group. The other limitation of this study is the absence of genetic evaluations. Finally, being a referral centre for cataract surgery, a greater number of patients may have visually significant cataract, even during the first examination. Consequently, there may be a higher number of patients with PSC. Other population-based studies may have different prevalence rates of cataracts.

In conclusion, we determined that a high proportion of individuals with presenile cataract were atopic. PSC cataract was the predominant type of cataract prevalent. PSC cataract had a stronger association for all the risk factors except for high myopia where nuclear cataract was predominant. On the basis of these findings, we will subsequently carry out a case-control study that will include other known risk factors for cataract (ie body mass index, smoking history, socioeconomic status) that may confound any association between atopy and cataract.

\section{References}

1 Hammond CJ, Duncan DD, Snieder H, de Lange M, West SK, Spector TD et al. The heritability of age-related cortical cataract: the twin eye study. Invest Ophthalmol Vis Sci 2001; 42: 601-605.

2 Klein BE, Klein R, Lee KE, Meuer SM. Socioeconomic and lifestyle factors and the 10-year incidence of age-related cataracts. Am J Ophthalmol 2003; 136: 506-512.

3 Burton M, Fergusson E, Hart A, Knight K, Lary D, Liu C. The prevalence of cataract in two villages of northern Pakistan with different levels of ultraviolet radiation. Eye 1997; 11: 95-101.

4 Brilliant LB, Grasset NC, Pokhrel RP, Kolstad A, Lepkowski JM, Brilliant GE et al. Associations among cataract prevalence, sunlight hours, and altitude in the Himalayas. Am J Epidemiol 1983; 118: 250-264.

5 Mohan M. Survey of blindness - India (1986-1989). In: Summary Results: Programme for the Control of Blindness. Ministry of Health and Family Welfare, Government of India: New Delhi, 1992.

6 Dandona L, Dandona R, Srinivas M, Giridhar P, Vilas K, Prasad MN et al. Blindness in the Indian state of Andhra Pradesh. Invest Ophthalmol Vis Sci 2001; 42: 908-916.

7 Chatterjee A, Milton RC, Thyle S. Prevalence and etiology of cataract in Punjab. Br J Ophthalmol 1982; 66: 35-42.

8 Thompson JR. The demand incidence of cataract in Asian immigrants to Britain and their descendants. Br J Ophthalmol 1989; 73: 950-954.

9 Mohan M, Sperduto RD, Angra SK, Milton RC, Mathur RL, Underwood BA et al. India-US case-control study of agerelated cataracts. India-US Case-Control Study Group. Arch Ophthalmol 1989; 107: 670-676.

10 Minassian DC, Mehra V, Verrey JD. Dehydrational crises: a major risk factor in blinding cataract. Br J Ophthalmol 1989; 73: 100-105.

11 Minassian DC, Mehra V, Jones BR. Dehydrational crises from severe diarrhea or heatstroke and risk of cataract. Lancet 1984; 7: 751-753.

12 Minassian DC, Mehra V, Reidy A. Childbearing and risk of cataract in young women: an epidemiological study in central India. Br J Ophthalmol 2002; 86: 548-550.

13 West SK, Valmadrid CT. Epidemiology of risk factors for age-related cataract. Surv Ophthalmol 1995; 39: 323-334.

14 Solberg Y, Rosner M, Belkin M. The association between cigarette smoking and ocular diseases. Surv Ophthalmol 1998; 42: 535-547.

15 Klein BE, Klein R, Lee KE, Danforth LG. Drug use and fiveyear incidence of age-related cataracts. The Beaver Dam Eye Study. Ophthalmology 2001; 108: 1670-1674.

16 Leske MC, Wu SY, Hennis A, Connell AM, Hyman L, Schachat A. Diabetes, hypertension, and central obesity as cataract risk factors in a black population. The Barbados Eye Study. Ophthalmology 1999; 106: 35-41.

17 Dolin PJ. Ultraviolet radiation and cataract: a review of the epidemiological evidence. Br J Ophthalmol 1994; 78: 478-482. 
18 Dolin PJ. Assessment of epidemiological evidence that exposure to solar ultraviolet radiation causes cataract. Doc Ophthalmol 1994-1995; 88: 327-337. Review.

19 Lesiewska-Junk H. Senile and presenile cataract. Survey of patients undergoing cataract surgery. Acta ophthalmologica 1994; 72: 602-605.

20 Mishra AV, Ramswamy MS, Orr AC. Causes of presenile cataracts extracted at the Halifax Infirmary Hospital, 1976-85. Can J Ophthalmol 1989; 24: 117-119.

21 Schwab IR, Armstrong MA, Friedman GD, Wong IG, Carpentieri AC, Dawson CR. Cataract extraction. Risk factors in a health maintenance organization population under 60 years of age. Arch Ophthalmol 1988; 106: 1062-1065.

22 Bhatnagar R, West Jr KP, Vitale S, Sommer A, Joshi S, Venkataswamy G. Risk of cataract and history of severe diarrheal disease in southern India. Arch Ophthalmol 1991; 109: 696-699.

23 Uehara M, Amemiya T, Arai M. Atopic cataracts in a Japanese population. With special reference to factors possibly relevant to cataract formation. Dermatologica 1985; 170: $180-184$.

24 Uehara M, Sato T. Atopic cataract induced by severe allergic contact dermatitis on the face. Dermatologica 1986; 172: 54-57.

25 Chen CC, Huang JL, Yang KD, Chen HJ. Atopic cataracts in a child with atopic dermatitis: a case report and review of the literature. Asian Pac J Allergy Immunol 2000; 18: 69-71.

26 Strzałka A, Przepiórkowski R. Cataract in an atopic dermatitis patient - case report and review of the literature. Klin Oczna 2006; 108: 443-445.

27 Garrity JA, Liesegang TJ. Ocular complications of atopic dermatitis. Can J Ophthalmol 1984; 19: 21-24.

28 Christensen JD. Frequency of cataract in atopic dermatitis. Acta Derm Venereol 1981; 61: 76-77.

29 Nagaki Y, Hayasaka S, Kadoi C. Cataract progression in patients with atopic dermatitis. J Cataract Refract Surg 1999; 25: 96-99.

30 Cowan A, Klauder JV. Frequency of occurrence of cataract in atopic dermatitis. Arch Ophthalmol 1950; 43: 759-768.

31 Amemiya T, Matsuda H, Uehara M. Ocular findings in atopic dermatitis with special reference to the clinical features of atopic cataract. Ophthalmologica 1980; 180: 129-132.
32 Matsuo T, Saito H, Matsuo N. Cataract and aqueous flare levels in patients with atopic dermatitis. Am J Ophthalmol 1997; 124: 36-39.

33 Brunsting LA, Reed WB, Bair HL. Occurrence of cataracts and keratoconus with atopic dermatitis. Arch Dermatol 1955; 72: 237-241.

34 Vasavada AR, Mamidipudi PR, Sharma PS. Morphology of and visual performance with posterior subcapsular cataract. J Cataract Refract Surg 2004; 30: 2097-2104.

35 Chen SN, Lin KK, Chao AN, Kuo YH, Ho JD. Nuclear sclerotic cataract in young patients in Taiwan. J Cataract Refract Surg 2003; 29: 983-988.

36 O' Donnell Jr FE, Maumenee AE. 'Unexplained' visual loss in axial myopia: cases caused by mild nuclear sclerotic cataract. Ophthalmic Surg 1980; 11: 99-101.

37 Black RL, Oglesby RB, von Sallmann L. Posterior subcapsular cataracts induced by corticosteroids in patients with rheumatoid arthritis. JAMA 1960; 174: 166-171.

38 Jick SS, Vasilakis-Scaramozza C, Maier WC. The risk of cataract among users of inhaled steroids. Epidemiology 2001; 12: 229-234.

39 Prchal J, Skalka H, Clements RS, Bradley EL, Conrad ME, Pittman C. Diabetes and risk of cataract development. Metab Pediatr Ophthalmol 1980; 4: 185-189.

40 Klein BE, Klein R, Moss SE. Prevalence of cataracts in a population-based study of persons with diabetes mellitus. Ophthalmology 1985; 92: 1191-1196.

41 Harding JJ, Harding RS, Egerton M. Risk factors for cataract in Oxfordshire: diabetes, peripheral neuropathy, myopia, glaucoma and diarrhoea. Acta Ophthalmol (Copenh) 1989; 67: 510-517.

42 Cruickshanks KJ, Klein BE, Klein R. Ultraviolet light exposure and lens opacities: the Beaver Dam Eye Study. Am J Public Health 1992; 82: 1658-1662.

43 Brilliant LB, Grasset NC, Pokhrel RP, Kolstad A, Lepkowski JM, Brilliant GE et al. Associations among cataract prevalence, sunlight hours, and altitude in the Himalayas. Am J Epidemiol 1983; 118: 250-264.

44 Rosenthal FS, Phoon C, Bakalian AE, Taylor HR. The ocular dose of ultraviolet radiation to outdoor workers. Invest Ophthalmol Vis Sci 1988; 29: 649-656. 